\title{
Notes from the Editor
}

Scarcely a day has passed in the last decade without reports appearing of yet another act of suicide terrorism (the subject matter of this issue's cover graphic) in the world's established and emerging hotspots. In "The Strategic Logic of Suicide Terrorism," Robert Pape posits that "Even if many suicide attackers are irrational or fanatical, the leadership groups that recruit and direct them are not." Rather, such attacks are intended to achieve specific political purposes. To examine these acts, Pape has assembled a database of suicide attacks worldwide, 1980-2001. His findings among other things, that suicide terrorism often "pays" from the perspective of group leaders because it leads governments to make concessions - will enable scholars to achieve a new understanding of this complex phenomenon. Nor does Pape shy away from considering the policy implications of his findings. Consequently, this important article is destined to inform not only scholarship but also policy-making for years to come.

The September 11 attacks "changed everything." That, at least, is the contention of many students of national and international security, and of high-level policymakers as well. As Brian Frederking puts it in "Constructing Post-Cold War Collective Security," the assumption is that "New threats from terrorist groups and weapons of mass destruction have transformed the international system" so thoroughly that, for example, President Bush's campaign pledges not to engage in nation-building or to become involved in military hostilities without a clear exit strategy are no longer operative. However, employing the tools of dialogical analysis to consider the debate over intervention in Kosovo in the late 1990s, Frederking uncovers themes that he deems "stunningly similar to the post-September 11 debates about the use of military force in Iraq." His analysis thus poses a fundamental challenge to the notion that September 11 "changed everything."

The authors of the third article in this issue consider a very different mode of dealing with political conflict, interparty competition. In "Electoral Institutions, Ethnopolitical Cleavages and Party Systems in Africa's Emerging Democracies," Shaheen Mozaffar, James R. Scarritt, and Glen Galaich probe the impacts of the size of legislative districts, the proximity of legislative and presidential elections, and the fragmentation of ethnopolitical groups on the structure of African party systems, as observed in 62 legislative elections. Consistent with their expectations, these authors uncover a set of contingent effects. That is, rather than determining that party systems are shaped either by the institutions governing electoral contestation or by underlying ethnopolitical cleavages, Mozaffar, Scarritt, and Galaich find that the impact of either set of forces depends upon the other set of forces. This complex pattern, they conclude, makes them cautiously optimistic about the future course of democracy in Africa.
In "Democracy, Inequality, and Inflation," Raj M. Desai, Anders Olofsgård, and Tarik M. Yousef pose a deceptively simple question: Do democracies suffer higher inflation than non-democracies? Analyzing data from 140 countries over the last four decades of the twentieth century, Desai, Olofsgård, and Yousef, find (much as Mozaffar, Scarritt, and Galaich do about the structure of African party systems) that the best general answer is "It depends." Only when a nation's level of income inequality is taken into account, they show, can the impact of democracy on inflation be understood, for the relationship between democracy and inflation actually reverses from countries where incomes are more equally distributed to those where they are less equally distributed. This finding sheds new light on question of why inflation has had such different political impacts in different parts of the world.

Economic policy is also the focus of Philip Keefer and David Stasavage's "The Limits of Delegation: Veto Players, Central Bank Independence and the Credibility of Monetary Policy." The emergence of independent central banks around the world has occasioned concern about the potential politicization of these powerful institutions and the resulting likelihood that the credibility of monetary policy could thereby be undermined. Keefer and Stasavage identify conditions under which credibility can be bolstered by a system of institutional checks and balances. They argue that a system in which the actions of one group can be "vetoed" by another semi-adversarial group can positively affect consumer confidence and thereby provide one basis for a stable currency. Methodologically, this is one of a growing number of articles that combine formal and statistical modes of analysis; theoretically, it advances the "veto player" perspective by specifying contextual elements that shape and constrain a government's ability to override the decisions of its semi-autonomous agencies.

In "New Politics and Class Politics in the Context of Austerity and Globalization: Welfare State Regress in 18 Countries 1975-1995," Walter Korpi and Joakim Palme sustain this focus on the interplay between politics and social forces - this time in the context of the impact of class-related parties on social welfare programs. If politics is, in the Lasswellian formulation, a matter of "who gets what, when, and how," then Korpi and Palme's focus is crucial. Taking issue with a prominent interpretation, Korpi and Palme contend that classbased political forces have remained important during an era of welfare state regress; a decline in the extension of welfare state policies does not reflect a decline in class-based politics, which continues to play a key role in the era of retrenchment.

The next two articles in this issue present text-based analyses of the thought of two very different political theorists. The first of these centers on the liberal ideal of freedom of choice, which is supposed to promote 
individuality. Poststructuralists criticize liberals for assuming that choice can be truly free; because being "normal" itself acquires value and guides behavior, choice is always constrained. In "Freedom and Normalization: Poststructuralism and the Liberalism of Michael Oakeshott," Jacob Segal analyzes the confrontation between liberalism and normalization through the lens of the thought of Oakeshott. One of Segal's contributions is to show that the problem of normalization arises from the perspective of radical critics of liberalism but also from that of Oakeshott hardly a radical critic of liberalism! Another is to show how Oakeshott reformulates liberalism in the course of grappling with the challenges to it that normalization poses.

A long-recognized dilemma of democratic politics involves the simultaneous needs for widespread participation in decision-making, on the one hand, and for expertise, on the other. This dilemma seems to arise in an especially acute form in the writings of Rousseau, the "theorist par excellence of participation" whose arguments for both majority rule and commissaires to set the legislative agenda have often been seen as irreconcilable. In "Rousseau on Agenda-Setting and Majority Rule," Ethan Putterman refutes such criticism by returning to Rousseau's writings on the role of representatives. Rousseau's thinking about representatives, Putterman argues, was consistent with his thinking about majority rule, and if proper checks on representatives are in place, the dual advantages of democratic participation and learned leadership can be simultaneously achieved.

A merger of Korpi and Palme's emphasis on distribution and Putterman's on representation occurs in Steven Ansolabehere, James M. Snyder, Jr., and Michael M. Ting's "Bargaining in Bicameral Legislatures: When and Why Does Malapportionment Matter?" The starting point for this analysis is the oftdocumented finding that the greater a jurisdiction's representation in a legislature, the greater its share of public expenditures. It follows that malapportionment can produce inequities in resource allocation a possibility that underlies much criticism of the U.S. Senate in particular. Strikingly, though, Ansolabehere, Snyder, and Ting contend that unequal representation, or "malapportionment," is not itself the cause of uneven distributions of resources; when a bicameral legislature distributes resources, the share of every jurisdiction's resources should be equal as long as, as is the case in the U.S. Congress, one chamber is not malapportioned and possesses authority to initiate spending legislation. The root causes of the uneven distribution of resources lie elsewhere, e.g., in supermajoritarian rules like cloture. Buttressed by empirical results that these authors have reported elsewhere, these analytical results have undeniable implications for what reforms should be pursued if the goal is to attain a more equitable distribution of resources.

Finally, in “Acting When Elected Officials Won't: Federal Courts and Civil Rights Enforcement in U.S. Labor Unions," Paul Frymer provides a well-developed analysis that may well lead many Americanists to re- think the importance of the judicial system in the United States. Drawing on archival and other historical sources from the middle of the twentieth century, Frymer builds a deep understanding of the circumstances surrounding the impact of U.S. courts on the racial integration of labor unions. Frymer contends that the courts alone forced unions to cease discriminatory practices. It was the courts that ruled discrimination illegal, that rewrote civil rights statutes, and forced unions to comply with these statutes - not Congress or the executive branch.

\section{INSTRUCTIONS TO CONTRIBUTORS}

\section{General Considerations}

The APSR strives to publish scholarly research of exceptional merit, focusing on important issues and demonstrating the highest standards of excellence in conceptualization, exposition, methodology, and craftsmanship. Because the APSR reaches a diverse audience of scholars and practitioners, authors must demonstrate how their analysis illuminates a significant research problem, or answers an important research question, of general interest in political science. For the same reason, authors must strive for a presentation that will be understandable to as many scholars as possible, consistent with the nature of their material.

The APSR publishes original work. Therefore, authors should not submit articles containing tables, figures, or substantial amounts of text that have already been published or are forthcoming in other places, or that have been included in other manuscripts submitted for review to book publishers or periodicals (including on-line journals). In many such cases, subsequent publication of this material would violate the copyright of the other publisher. The APSR also does not consider papers that are currently under review by other journals or duplicate or overlap with parts of larger manuscripts that have been submitted to other publishers (including publishers of both books and periodicals). Submission of manuscripts substantially similar to those submitted or published elsewhere, or as part of a book or other larger work, is also strongly discouraged. If you have any questions about whether these policies apply in your particular case, you should discuss any such publications related to a submission in a cover letter to the Editor. You should also notify the Editor of any related submissions to other publishers, whether for book or periodical publication, that occur while a manuscript is under review by the APSR and which would fall within the scope of this policy. The Editor may request copies of related publications.

If your manuscript contains quantitative evidence and analysis, you should describe your procedures in sufficient detail to permit reviewers to understand and evaluate what has been done and, in the event that the article is accepted for publication, to permit other scholars to carry out similar analyses on other data sets. For example, for surveys, at the least, sampling procedures, response rates, and question wordings should 
be given; you should calculate response rates according to one of the standard formulas given by the American Association for Public Opinion Research, Standard Definitions: Final Dispositions of Case Codes and Outcome Rates for RDD Telephone Surveys and InPerson Household Surveys (Ann Arbor, MI: AAPOR, 1998). This document is available on the Internet at $<$ http://www.aapor.org/ethics/stddef.html $>$. For experiments, provide full descriptions of experimental protocols, methods of subject recruitment and selection, subject payments and debriefing procedures, and so on. Articles should be self-contained, so you should not simply refer readers to other publications for descriptions of these basic research procedures.

Please indicate variables included in statistical analyses by capitalizing the first letter in the variable name and italicizing the entire variable name the first time each is mentioned in the text. You should also use the same names for variables in text and tables and, wherever possible, should avoid the use of acronyms and computer abbreviations when discussing variables in the text. All variables appearing in tables should have been mentioned in the text and the reason for their inclusion discussed.

As part of the review process, you may be asked to submit additional documentation if procedures are not sufficiently clear; the review process works most efficiently if such information is given in the initial submission. If you advise readers that additional information is available, you should submit printed copies of that information with the manuscript. If the amount of this supplementary information is extensive, please inquire about alternate procedures.

The APSR uses a double-blind review process. You should follow the guidelines for preparing anonymous copies in the Specific Procedures section below.

Manuscripts that are largely or entirely critiques or commentaries on previously published $A P S R$ articles will be reviewed using the same general procedures as for other manuscripts, with one exception. In addition to the usual number of reviewers, such manuscripts will also be sent to the scholar(s) whose work is being criticized, in the same anonymous form that they are sent to reviewers. Comments from the original author(s) to the Editor will be invited as a supplement to the advice of reviewers. This notice to the original author(s) is intended (1) to encourage review of the details of analyses or research procedures that might escape the notice of disinterested reviewers; (2) to enable prompt publication of critiques by supplying criticized authors with early notice of their existence and, therefore, more adequate time to reply; and (3) as a courtesy to criticized authors. If you submit such a manuscript, you should therefore send as many additional copies of their manuscripts as will be required for this purpose.

Manuscripts being submitted for publication should be sent to Lee Sigelman, Editor, American Political Science Review, Department of Political Science, The George Washington University, 2201 G Street N.W., Room 507, Washington, DC 20052. Correspondence concerning manuscripts under review may be sent to the same address or e-mailed to apsr@gwu.edu.

\section{Manuscript Formatting}

Manuscripts should not be longer than 45 pages including text, all tables and figures, notes, references, and appendices. This page size guideline is based on the U.S. standard $8.5 \times 11$-inch paper; if you are submitting a manuscript printed on longer paper, you must adjust accordingly. The font size must be at least 11 points for all parts of the paper, including notes and references. The entire paper, including notes and references, must be double-spaced, with the sole exception of tables for which double-spacing would require a second page otherwise not needed. All pages should be numbered in one sequence, and text should be formatted using a normal single column no wider than 6.5 inches, as is typical for manuscripts (rather than the double-column format of the published version of the APSR), and printed on one side of the page only. Include an abstract of no more than 150 words. The APSR style of embedded citations should be used, and there must be a separate list of references at the end of the manuscript. Do not use notes for simple citations. These specifications are designed to make it easier for reviewers to read and evaluate papers. Papers not adhering to these guidelines are subject to being rejected without review.

For submission and review purposes, you may place footnotes at the bottom of the pages instead of using endnotes, and you may locate tables and figures (on separate pages and only one to a page) approximately where they fall in the text. However, manuscripts accepted for publication must be submitted with endnotes, and with tables and figures on separate pages at the back of the manuscript with standard indications of text placement, e.g., [Table 3 about here]. In deciding how to format your initial submission, please consider the necessity of making these changes if your paper is accepted. If your paper is accepted for publication, you will also be required to submit camera-ready copy of graphs or other types of figures. Instructions will be provided.

For specific formatting style of citations and references, please refer to articles in the most recent issue of the APSR. For unusual style or formatting issues, you should consult the latest edition of The Chicago Manual of Style. For review purposes, citations and references need not be in specific $A P S R$ format, although some generally accepted format should be used, and all citation and reference information should be provided.

\section{Specific Procedures}

Please follow these specific procedures for submission:

1. You are invited to submit a list of scholars who would be appropriate reviewers of your manuscript. The Editor will refer to this list in selecting reviewers, though there obviously can be no guarantee that those you suggest will actually be chosen. Do not list anyone who has already commented on your paper or an earlier version of it, or any of your current or recent collaborators, 
institutional colleagues, mentors, students, or close friends.

2. Submit five copies of manuscripts and a diskette containing a pdf file of the anonymous version of the manuscript. If you cannot save the manuscript as a pdf, just send in the diskette with the wordprocessed version. Please ensure that the paper and diskette versions you submit are identical; the diskette version should be of the anonymous copy (see below). Please review all pages of all copies to make sure that all copies contain all tables, figures, appendices, and bibliography mentioned in the manuscript and that all pages are legible. Label the diskette clearly with the (first) author's name and the title of the manuscript (in abridged form if need be), and identify the word processing program and operating system.

3. To comply with the APSR's procedure of doubleblind peer reviews, only one of the five copies submitted should be fully identified as to authorship and four should be in anonymous format.

4. For anonymous copies, if it is important to the development of the paper that your previous publications be cited, please do this in a way that does not make the authorship of the submitted paper obvious. This is usually most easily accomplished by referring to yourself in the third person and including normal references to the work cited in the list of references. In no circumstances should your prior publications be included in the bibliography in their normal alphabetical location but with your name deleted. Assuming that text references to your previous work are in the third person, you should include full citations as usual in the bibliography. Please discuss the use of other procedures to render manuscripts anonymous with the Editor prior to submission. You should not thank colleagues in notes or elsewhere in the body of the paper or mention institution names, web page addresses, or other potentially identifying information. All acknowledgments must appear on the title page of the identified copy only. Manuscripts that are judged not anonymous will not be reviewed.

5. The first page of the four anonymous copies should contain only the title and an abstract of no more than 150 words. The first page of the identified copy should contain (a) the name, academic rank, institutional affiliation, and contact information (mailing address, telephone, fax, e-mail address) for all authors; (b) in the case of multiple authors, an indication of the author who will receive correspondence; (c) any relevant citations to your previous work that have been omitted from the anonymous copies; and (d) acknowledgments, including the names of anyone who has provided comments on the manuscript. If the identified copy contains any unique references or is worded differently in any way, please mark this copy with "Contains author citations" at the top of the first page.

No copies of submitted manuscripts can be returned.

\section{ELECTRONIC ACCESS TO THE APSR}

Back issues of the APSR are available in several electronic formats and through several vendors. Except for the last three years (as an annually "moving wall"), back issues of the APSR beginning with Volume 1, Number 1 (November 1906), are available on-line through JSTOR (http://wwwjstor.org/). At present, JSTOR's complete journal collection is available only via institutional subscription, e.g., through many college and university libraries. For APSA members who do not have access to an institutional subscription to JSTOR, individual subscriptions to its APSR content are available. Please contact Member Services at APSA for further information, including annual subscription fees.

Individual members of the American Political Science Association can access recent issues of the APSR and $P S$ through the APSA website (www.apsanet.org) with their username and password. Individual nonmember access to the online edition will also be available, but only through institutions that hold either a print-plus-electronic subscription or an electronic-only subscription, provided the institution has registered and activated its online subscription.

Full text access to current issues of both the APSR and $P S$ is also available on-line by library subscription from a number of database vendors. Currently, these include University Microfilms Inc. (UMI) (via its CDROMs General Periodicals Online and Social Science Index and the on-line database ProQuest Direct), Online Computer Library Center (OCLC) (through its on-line database First Search as well as on CD-ROMs and magnetic tape), and the Information Access Company (IAC) (through its products Expanded Academic Index, InfoTrac, and several on-line services [see below]). Others may be added from time to time.

The $A P S R$ is also available on databases through six online services: Datastar (Datastar), Business Library (Dow Jones), Cognito (IAC), Encarta Online Library (IAC), IAC Business (Dialog), and Newsearch (Dialog).

The editorial office of the APSR is not involved in the subscription process to either JSTOR for back issues or the other vendors for current issues. Please contact APSA, your reference librarian, or the database vendor for further information about availability.

\section{BOOK REVIEWS}

The APSR no longer contains book reviews. As of 2003, book reviews have moved to Perspectives on Politics. All books for review should be sent directly to the Perspectives on Politics Book Review Editors, Susan Bickford and Greg McAvoy. The address is Susan Bickford and Gregory McAvoy, Perspectives on Politics Book Review Editors, Department of Political Science, University of North Carolina at Chapel Hill, CB No. 3265, Chapel Hill, NC 27599-3265. E-mail: apsrbook@unc.edu.

If you are the author of a book you wish to be considered for review, please ask your publisher to send a copy 
to the Perspectives on Politics Book Review Editors per the mailing instructions above. If you are interested in reviewing books for Perspectives on Politics, please send your vita to the Book Review Editors; you should not ask to review a specific book.

\section{OTHER CORRESPONDENCE}

The American Political Science Association's address, telephone, and fax are 1527 New Hampshire Avenue, N.W., Washington, D.C. 20036, (202) 483-2512 (voice), and (202) 483-2657 (fax). E-mail: apsa@apsanet.org. Please direct correspondence as follows.

Information, including news and notes, for PS:

Dr. Robert J-P. Hauck, Editor, $P S$

E-mail: rhauck@apsanet.org

Circulation and subscription correspondence (domestic claims for nonreceipt of issues must be made within four months of the month of publication; overseas claims, within eight months):

Elizabeth Weaver Engel,

Director of Member Services

E-mail: membership@apsanet.org

Reprint permissions: E-mail: reprints@apsanet.org

Advertising information and rates:

Advertising Coordinator, Cambridge University Press

E-mail: journals_advertising@cup.org

\section{EXPEDITING REQUESTS FOR COPYING APSR AND PS ARTICLES FOR CLASS USE AND OTHER PURPOSES}

\section{Class Use}

The Comprehensive Publisher Photocopy Agreement between APSA and the Copyright Clearance Center (CCC) permits bookstores and copy centers to receive expedited clearance to copy articles from the APSR and $P S$ in compliance with the Association's policies and applicable fees. The general fee for articles is 75 cents per copy. However, current Association policy levies no fee for the first 10 copies of a printed artide, whether in course packs or on reserve. Smaller classes that rely heavily on articles (i.e., upper-level undergraduate and graduate classes) can take advantage of this provision, and faculty ordering 10 or fewer course packs should bring it to the attention of course pack providers. APSA policy also permits free use of the electronic library reserve, with no limit on the number of students who can access the electronic reserve. Both large and small classes that rely on these articles can take advantage of this provision. The CCC's address, telephone, and fax are 222 Rosewood Drive, Danvers, MA 01923, (978) 750-8400 (voice), and (978) 750-4474 (fax). This agreement pertains only to the reproduction and distribution of APSA materials as hard copies (e.g., photocopies, microfilm, and microfiche).

The Association of American Publishers (AAP) has created a standardized form for college faculty to submit to a copy center or bookstore to request copyrighted material for course packs. The form is available through the CCC, which will handle copyright permissions.

APSA also has a separate agreement pertaining to CCC's Academic E-Reserve Service. This agreement allows electronic access for students and instructors of a designated class at a designated institution for a specified article or set of articles in electronic format. Access is by password for the duration of a class.

Please contact your librarian, the CCC, or the APSA Reprints Department for further information.

\section{APSR Authors}

If you are the author of an APSR article, you may use your article in course packs or other printed materials without payment of royalty fees and you may post it at personal or institutional web sites as long as the APSA copyright notice is included.

\section{Other Uses of APSA-Copyrighted Materials}

For any further copyright issues, please contact the APSA Reprints Department.

\section{INDEXING}

Articles appearing in the APSR before June 1953 were indexed in The Reader's Guide to Periodical Literature. Current issues are indexed in ABC Pol Sci; America, History and Life 1954-; Book Review Index; Current Contents: Social and Behavioral Sciences; EconLit; Energy Information Abstracts; Environmental Abstracts; Historical Abstracts; Index of Economic Articles; Information Service Bulletin; International Index; International Political Science Abstracts; the Journal of Economic Literature; Periodical Abstracts; Public Affairs; Public Affairs Information Service International Recently Published Articles; Reference Sources; Social Sciences and Humanities Index; Social Sciences Index; Social Work Research and Abstracts; and Writings on American History. Some of these sources may be available in electronic form through local public or educational libraries. Microfilm of the APSR, beginning with Volume 1, and the index of the APSR through 1969 are available through University Microfilms Inc., 300 North Zeeb Road, Ann Arbor, MI 48106 (www.umi.com). The Cumulative Index to the American Political Science Review, Volumes 63 to 89: 1969-95, is available through the APSA. 